\title{
Long term ionospheric electron content variations over Delhi
}

\author{
J. K. Gupta and Lakha Singh \\ Radio and Atmospheric Sciences Division, National Physical Laboratory, Dr K S Krishnan Marg, New Delhi-110012, India
}

Received: 10 May 2000 / Revised: 5 September 2000 / Accepted: 25 September 2000

\begin{abstract}
Ionospheric electron content (IEC) observed at Delhi (geographic co-ordinates: $28.63^{\circ} \mathrm{N}, 77.22^{\circ} \mathrm{E}$; geomagnetic co-ordinates: $19.08^{\circ} \mathrm{N}, 148.91^{\circ} \mathrm{E}$; dip Latitude $24.8^{\circ} \mathrm{N}$ ), India, for the period $1975-80$ and $1986-$ 89 belonging to an ascending phase of solar activity during first halves of solar cycles 21 and 22 respectively have been used to study the diurnal, seasonal, solar and magnetic activity variations. The diurnal variation of seasonal mean of IEC on quiet days shows a secondary peak comparable to the daytime peak in equinox and winter in high solar activity. IEC $_{\max }$ (daytime maximum value of IEC, one per day) shows winter anomaly only during high solar activity at Delhi. Further, IEC $\mathrm{Eax}_{\max }$ shows positive correlation with $\mathrm{F}_{10.7}$ up to about 200 flux units at equinox and 240 units both in winter and summer; for greater $\mathrm{F}_{10.7}$ values, $\mathrm{IEC}_{\max }$ is substantially constant in all the seasons. IEC $\mathrm{Iax}_{\text {ax }}$ and magnetic activity $\left(A_{p}\right)$ are found to be positively correlated in summer in high solar activity. Winter IEC $_{\max }$ shows positive correlation with $A_{p}$ in low solar activity and negative correlation in high solar activity in both the solar cycles. In equinox $\mathrm{IEC}_{\max }$ is independent of $A_{p}$ in both solar cycles in low solar activity. A study of day-to-day variations in $\mathrm{IEC}_{\max }$ shows single day and alternate day abnormalities, semi-annual and annual variations controlled by the equatorial electrojet strength, and 27-day periodicity attributable to the solar rotation.
\end{abstract}

Key words: Ionosphere (equatorial ionosphere) Magnetospheric physics (magnetosphere - ionosphere interactions) - Radio science (ionospheric physics)

\section{Introduction}

Remote sensing of the earth from satellites or of space features from the ground is affected by the ionosphere

Correspondence to: J. K. Gupta due to time delay, refraction, diffraction and scattering of waves in the ionosphere. Because there are large diurnal, seasonal and other solar-induced variations in the ionosphere, users of radio systems must cope with large fluctuations in ionospheric effects. Ionospheric electron content (IEC) is a parameter which is used to monitor the temporal and spatial behaviour of the ionosphere. It is easily measured using satellite transmissions in the VHF band. It is subjected to significant dynamical changes, particularly in the equatorial and low latitude regions, owing to the changes in the electric fields (Kelley, 1989). At mid-latitudes, these effects are not significantly seen, as the dynamical processes are mainly controlled by neutral winds in that region. Studies of diurnal and seasonal variations of IEC (in units of $10^{16}$ electrons $/ \mathrm{m}^{2}$, denoted by TECU) as measured from orbiting as well as geostationary satellites have been made by a large number of workers worldwide, and summarised in some excellent reviews by Tyagi and Das Gupta (1990), Davies (1991) and Rama Rao et al. (1994). Recently Chakraborty et al. (1999) have reported 13 years' observations of postsunset total electron content and scintillations, emphasising the coupling between equatorial and low-latitude dynamics.

This work analyses the diurnal, seasonal, solar and magnetic activity variations of IEC observed at Delhi (geographic co-ordinates: $28.63^{\circ} \mathrm{N}, 77.22^{\circ} \mathrm{E}$; geomagnetic coordinates: $19.08^{\circ} \mathrm{N}, 148.91^{\circ} \mathrm{E}$ ) during the period $1975-80$ and 1986-89 belonging to solar cycles 21 and 22 respectively. IEC observations at Delhi were made by means of the Faraday rotation technique using the geostationary satellites ATS-6, Symphonie-II and ETSII. In addition, the characteristics of day-to-day variability in IEC $_{\max }$ (the daytime maximum values of IEC, one per day) at Delhi are discussed and compared with those of other low-latitude stations. An effort has also been made to explore the relationship of IEC $_{\max }$ with magnetic activity $\left(A_{p}\right)$, solar flux $\left(\mathrm{F}_{10.7}\right)$ and equatorial electrojet strength measured by the parameter $\Delta H$, where $H$ is the horizontal component of geomagnetic field in nano Tesla (nT) units. 


\section{Data and method of analysis}

Faraday rotation (FR) of signals from geostationary satellites viz.; ATS-6 at $140 \mathrm{MHz}$ for the period October 1975-July 1976, Symphonie-II at $137 \mathrm{MHz}$ for the period May 1978-April 1979 and ETS-II at $136 \mathrm{MHz}$ from May 1979 to December 1980, and then again for ETS-II from March 1986 to December 1989 recorded at Delhi, have been utilised for the present study. The daytime maximum values of IEC $\left(\right.$ IEC $_{\max }$ ) have been examined on a daily basis. The daily values of equatorial electrojet strength parameter $(\Delta H)$ have been computed using the scheme suggested by Chandra and Rastogi (1974), according to which electrojet strength is determined by the term $H$ (equator) - $H$ (away from equator). In the present case, Trivandrum (geographic co-ordinates: $8.48^{\circ} \mathrm{N}, 76.95^{\circ} \mathrm{E}$; geomagnetic co-ordinates: $0.92^{\circ} \mathrm{S}, 146.37^{\circ} \mathrm{E}$; magnetic latitude $\left.=0.3^{\circ} \mathrm{N}\right)$ is taken as an equatorial station and Alibag (geographic co-ordinates: $18.39^{\circ} \mathrm{N}, 72.55^{\circ} \mathrm{E}$; geomagnetic co-ordinates: $9.63^{\circ} \mathrm{N}, 143.6^{\circ} \mathrm{E}$; magnetic latitude $=9.5^{\circ} \mathrm{N}$ ) as a low-latitude station. Figure 1 shows a map containing the locations of IEC station (Delhi) and the stations used in the calculations of the electrojet strength (Trivandrum and Alibag) alongwith their geographic co-ordinates and dip latitudes. It is well known that IEC at stations in the equatorial anomaly region can be affected by variations in electrojet strength through the "fountain effect", with a delay of 1 to $4 \mathrm{~h}$ and a maximum probability of a delay of about $3 \mathrm{~h}$ (Malkiat Singh et al., 1979). In the present analysis, in order to see the effect of the electrojet strength in causing a variation on the value of IEC diurnal maximum, $\mathrm{IEC}_{\max }$, at a low latitude (Delhi), the diffusion time is taken as $3 \mathrm{~h}$; that is, if IEC $_{\max }$, at Delhi corresponds to the hour $t$, then the value of electrojet strength is taken for the hour $(t-3)$.

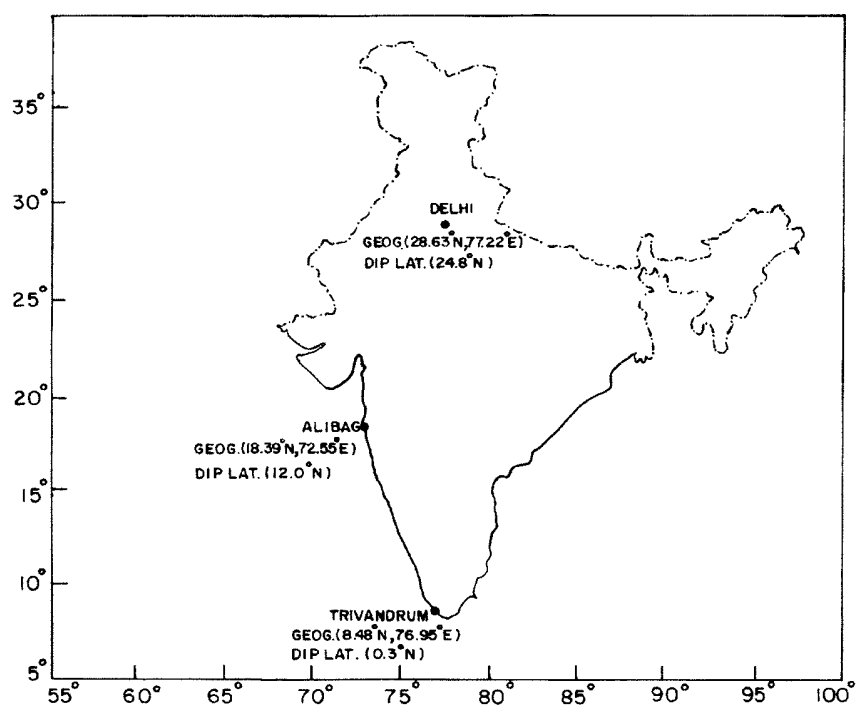

Fig. 1. A map showing the location of IEC station (Delhi) and the stations used in the calculation of electrojet strength (Trivandrum and Alibag)

\section{Morphology of ionospheric electron content}

\subsection{Diurnal variation of ionospheric electron content}

To study the diurnal variation of IEC during high solar activity at Delhi, international quiet days (10 days each month) have been selected. Hourly values of IEC have been computed from 0000 to 1600 and values at fiveminute intervals from 1605 to 2100 (to study the postsunset secondary maximum), and then hourly values again from 2100 to $2300 \mathrm{~h}$ IST for each day during 1979-80 and 1988-89 which are high solar activity periods. Then the monthly and seasonal mean of IEC is calculated. Figure 2a, b shows the seasonal mean (middle curve), upper quartile ( $\sigma_{95}$, upper curve) and lower quartile ( $\sigma_{95}$, lower-most curve) for quiet days in summer, winter and equinox seasons of 1979-80 and 1988-89 respectively. Upper and lower curves show the confidence level limits between which $95 \%$ of the IEC values lie. Diurnal variation of IEC during low solar activity has been reported by Garg et al. (1977). These studies show that though the behaviour of IEC in summer in high solar activity is similar to that reported by Garg et al. (1977) in low solar activity, it is considerably different in winter and equinox seasons. In winter and equinox a secondary peak called postsunset secondary maximum (PSSM) is found to occur around 2000 h, as shown in Fig 2a, b. The amplitude of the secondary peak is comparable to the daytime peak being about $90 \%$ and $84 \%$ in the equinoxes of 1979 and 1989 respectively, whereas in the winters of $1979-80$ and $1988-89$ it is $75 \%$ and $73 \%$ respectively. Garg et al. (1983) also reported post-sunset enhancements in IEC at $16^{\circ} \mathrm{N}$ or higher geomagnetic latitudes during high solar activity. They attributed it to the development and decay of the post-sunset equatorial anomaly which is primarily controlled by the meridional winds in association with $\mathbf{E} \times \mathbf{B}$ drifts. Lakha Singh et al. (1996) computed the diurnal variation of Faraday rotation for low (1975-76) and high solar activity (1980) periods from option-II of the International Reference Ionosphere (IRI) model (Bilitza, 1990) and found that IRI model does not predict the post-sunset secondary maximum.

\subsection{Seasonal anomaly in IEC}

To study the effect of seasons, solar and magnetic activity on ionospheric electron content, the daytime maximum of IEC $\left(\right.$ IEC $\left._{\max }\right)$ has been averaged on a seasonal basis in each of the two solar cycles 21 and 22 . It is found that the value of daytime IEC $_{\max }$ undergoes appreciable change in the course of different seasons of the year. As seen from Table 1 during low solar activity, the winter $\mathrm{IEC}_{\max }$ is appreciably lower compared to summer and equinox $\mathrm{IEC}_{\max }$. As the solar activity increases $\left(\mathrm{F}_{10.7}>100\right)$, the winter $\mathrm{IEC}_{\max }$ overtakes that of the summer; giving rise to the 'winter anomaly' or the 'seasonal anomaly'. Equinoctial $\mathrm{IEC}_{\max }$ is greater than both summer as well as winter IEC $_{\max }$ during all solar activity periods at Delhi except for 1980 when it is 


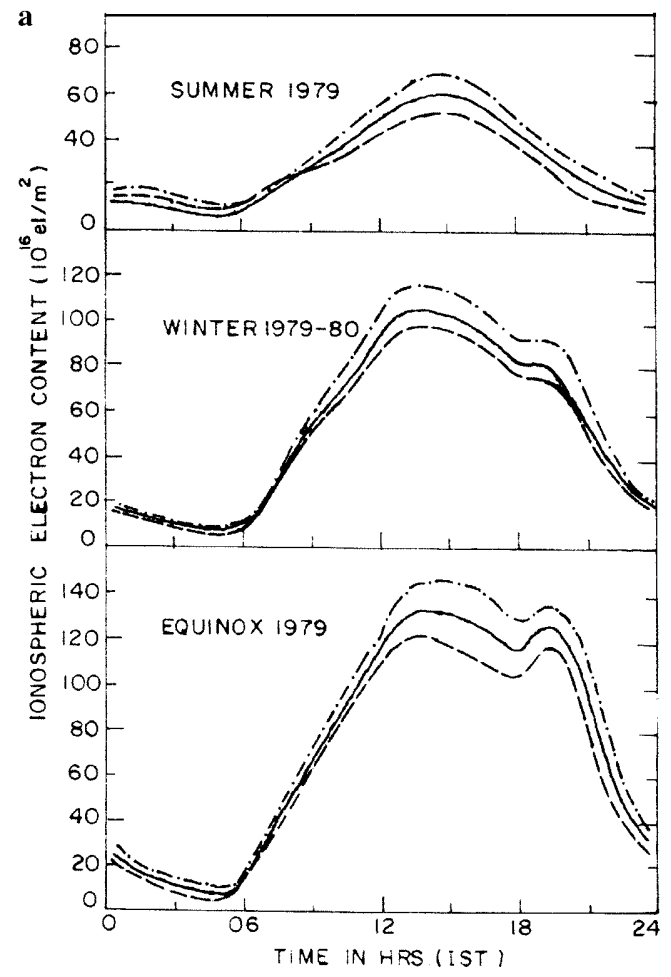

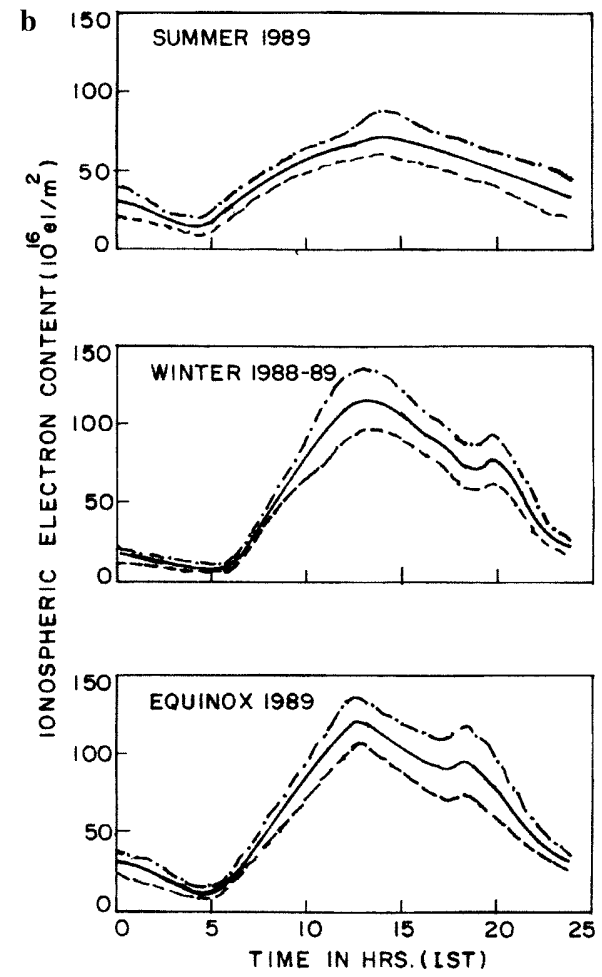

Fig. 2. a Diurnal variation of average IEC showing mean (solid curve), Upper quartile $\left(\sigma_{95}\right.$, dot dashed curve) and lower quartile ( $\sigma_{95}$, dashed curve) for quiet days of summer 1979, winter 1979-80 and equinox 1979 b Shows same but for quiet days of summer 1989, winter 1988-89 and equinox 1989
Table 1. Average daytime $\operatorname{IEC}_{\max }\left(10^{16} \mathrm{el} / \mathrm{m}^{2}\right)$

\begin{tabular}{llrrrrrrr}
\hline Seasons & $1975-76$ & 1978 & 1979 & 1980 & 1986 & 1987 & 1988 & 1989 \\
\hline Summer & 30 & 49 & 62 & 80 & 32 & 37 & 58 & 76 \\
Winter & 24 & 91 & 110 & 132 & 25 & 50 & 120 & 140 \\
Equinox & 40 & 110 & 130 & 132 & 42 & 63 & 135 & 150 \\
\hline
\end{tabular}

equal to winter. The absence of seasonal anomaly at Delhi during 1975-76 was reported by Garg et al. (1977). The observational data for the period 1986-89 confirm the earlier findings of Bhuyan et al. (1983). However, Lakha Singh et al. (1996) found that IRI (1990) model does not predict the seasonal anomaly in any type of solar activity.

Modi and Iyer (1988) also reported low IEC $_{\max }$ values in summer during 1980. Davies (1991) using GPS satellite time delay measurements, at Boulder (geographic co-ordinates: $40^{\circ} \mathrm{N}, 254.7^{\circ} \mathrm{E}$; geomagnetic coordinates: $48.8^{\circ} \mathrm{N}, 223.4^{\circ} \mathrm{E}$ ), Colorado, USA, has also reported higher $\mathrm{IEC}_{\max }$ in winter than in summer, and attributed this to increased plasma loss. Bhuyan (1992) and Huang and Cheng (1995), using IEC data of Lunping (geographic co-ordinates: $25^{\circ} \mathrm{N}, 121.2^{\circ} \mathrm{E}$; geomagnetic co-ordinates: $14.3^{\circ} \mathrm{N}, 191.3^{\circ} \mathrm{E}$ ), Taiwan, for the descending phase of solar activity during 1979-83, have found higher values of $\mathrm{IEC}_{\max }$ in winter than in summer in moderate and high solar activity conditions. Rama Rao et al. (1994) have also reported a winter anomaly during high solar activity at Waltair (geographic co-ordinates: $17.44^{\circ} \mathrm{N}, 83.23^{\circ} \mathrm{E}$; geomagnetic coordinates: $7.38^{\circ} \mathrm{N}, 153.37^{\circ} \mathrm{E}$ ). Torr et al. (1980) found the daytime F-region winter anomaly at mid-latitudes.
Most of the contribution to ionospheric electron content comes from the F-region. In F-region, electrons are produced by the photo-ionisation of atomic oxygen; the radiation absorbed by molecular nitrogen does not contribute appreciably to the observed ionisation because molecular ions are short-lived in the F-region. Consequently a change in the concentrations of these gases can alter the effective production as well as the loss rate which depends on the concentration of molecular gases. Rishbeth and Setty (1961) suggested that the seasonal changes result from changes in the ratio of the concentration of atomic oxygen and molecular nitrogen in the F-region. Yeh and Liu (1976) showed that the ratio $\mathrm{O} / \mathrm{N}_{2}$ increases in winter as compared to that in summer in high solar activity. Titheridge and Buonsanto (1983) reported that changes in the composition and in the zenith angle can account for the seasonal anomaly. Torr et al. (1980) and Richards and Torr (1986) have shown through model computations that vibrational excitation of $\mathrm{N}_{2}$ can decrease the daytime peak $\mathrm{O}^{+}$ density by more than a factor of 2 during summer, whereas the decrease is less than $10 \%$ during winter at solar maximum. Thus increase of the vibrationally excited $\mathrm{N}_{2}$ with increasing solar activity can also contribute to the increase of winter anomaly in $\mathrm{IEC}_{\max }$. Titheridge (1995) mentioned that strong downward winds occur during the daytime in summer, particularly at latitudes near $30^{\circ}$, producing daytime densities that are appreciably lower than in winter. In high solar activity, the concentration of atomic oxygen in the winter hemisphere is more than twice that in the summer hemisphere. The cause of an atomic oxygen-rich winter atmosphere is believed to be due to the global meridional wind. The thermospheric winds transport freshly 
produced atomic oxygen (in the summer hemisphere) to the winter hemisphere. Since the production time is large compared with the transport time, as observed by Yeh and Liu (1976), this process more than compensates for the expected higher value of $\mathrm{IEC}_{\max }$ that would otherwise be expected in summer, and there is more $\mathrm{IEC}_{\max }$ in winter than in summer in high solar activity.

\subsection{Solar activity control on IEC}

As solar UV radiation is the atmosphere's primary energy source, its variability is expected to cause changes in the atmospheric temperature, dynamics and composition. The part of the UV spectrum important for the production of the Earth's ionosphere is the EUV spectrum and $\mathrm{H}$ Lyman- $\alpha(121.6 \mathrm{~nm})$, because these radiations ionise the primary atmospheric constituents $\mathrm{O}, \mathrm{O}_{2}, \mathrm{~N}_{2}, \mathrm{NO}, \mathrm{He}$ and $H$. Information about the variability of EUV and Lyman- $\alpha$ is necessary for many studies of ionospheric variability. However, because reliable time series of EUV and Lyman- $\alpha$ irradiances are not readily available for long periods (in contrast to the ready availability for $10.7 \mathrm{~cm}$ solar flux data), solar emission data at longer wavelengths, by means of the $10.7 \mathrm{~cm}$ solar flux index $\left(\mathrm{F}_{10.7}\right)$, is most frequently used for this purpose.

To study the solar cycle variation of maximum electron content observed on any day, IEC $_{\max }$ values (one per day) corresponding to $\Sigma K_{p}<15$ are chosen to minimise the effect of magnetic activity. Data were grouped into three seasons as usual, i.e. summer (May, June, July and August), winter (November, December, January and February) and equinox (March, April, September and October) for each solar cycle. Most of the previous workers, e.g. Titheridge (1973), Koparkar (1987), Rao et al. (1988), Dabas et al. (1993), Balan et al. (1993) and Prasad and Rama Rao (1993) have shown a linear relationship of IEC $_{\max }$ with $\mathrm{F}_{10.7}$ up to about 200 flux units, and then a saturation. In the present study separate critical examinations are made of $\mathrm{IEC}_{\max }$ and $F_{10.7}$. After comparing the results of the two examinations, preference is given to using the 2 nd degree polynomial in curve-fitting of the data, because this led to minimal estimated standard errors. As IEC $\mathrm{Eax}_{\max }$ was found to be independent of solar flux up to about 60 units, the independent variable is taken as $F_{10.7}-60$ instead of $F_{10.7}$. This gave a reasonable value of IEC $_{\max }$ at lower values of $F_{10.7}$ flux. The study shows the following results.

3.3.1 Solar cycle-21 (1975-80) results. 1. In equinox, the diurnal IEC $_{\max }$ increases with $\mathrm{F}_{10.7}$ up to about 200 flux units, after which IEC $_{\max }$ saturates at a value of approximately 140 TECU, as shown in Fig 3a. The correlation coefficient and the second degree polynomial are given by $r=0.88$ and $y=5.51+1.63 \mathrm{X}-0.005 \mathrm{X}^{2}$ respectively, where $y$ represents $\mathrm{IEC}_{\max }$ and $\mathrm{X}$ represents solar flux. The correlation coefficient for linear fitting was found to be 0.84 .

2. In winter, IEC $_{\max }$ increases with $\mathrm{F}_{10.7}$ up to about 240 units, after which the increase is found to be slowly approaching a value of approximately $140 \mathrm{TECU}$, as

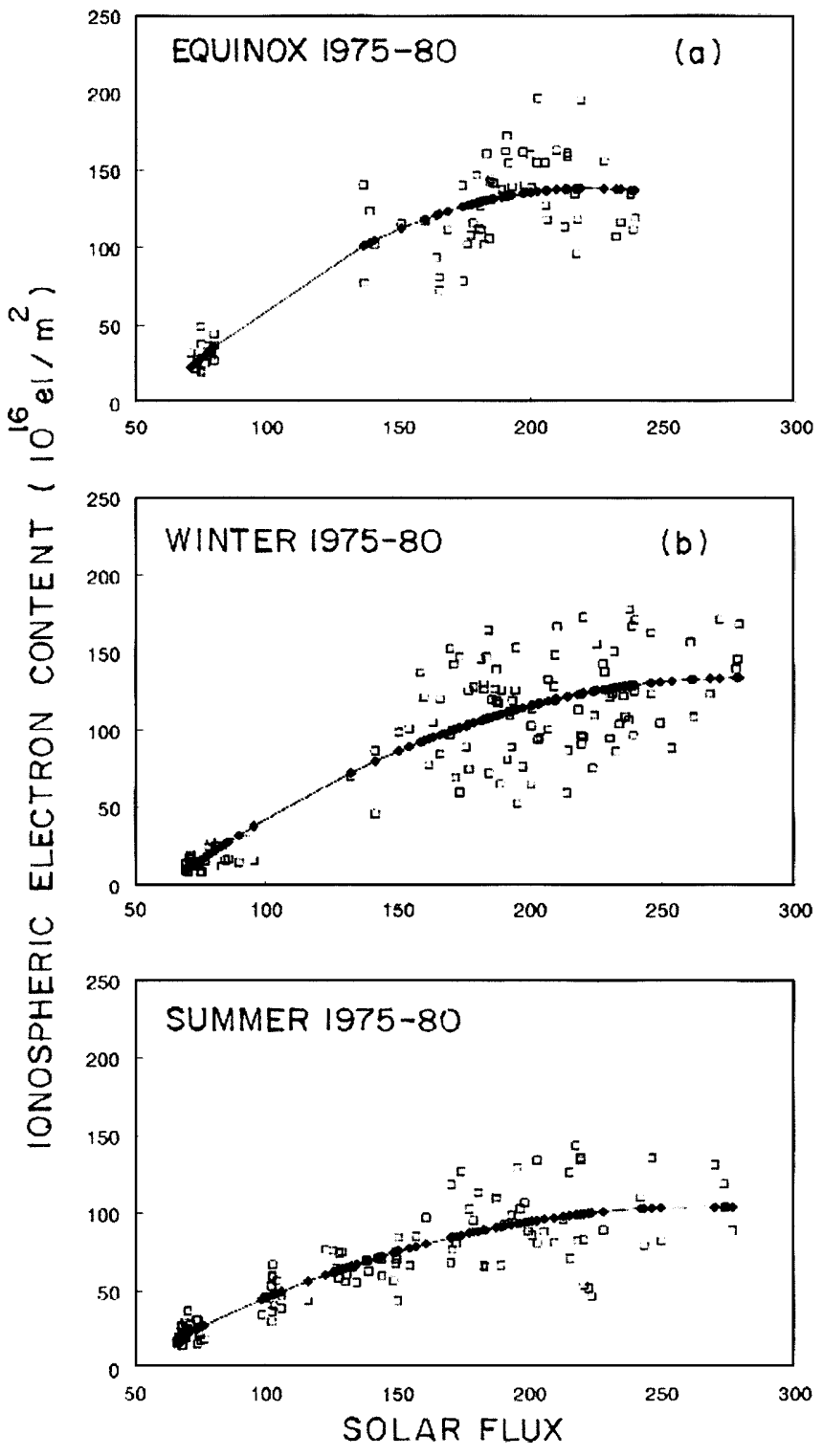

Fig. 3a-c. Variation of IEC $_{\max }$ with solar flux $\left(F_{10.7}\right)$ in solar cycle 21 for a equinox, $\mathbf{b}$ winter and $\mathbf{c}$ summer (the black diamonds show the points of 2 nd degree polynomial fitting)

shown in Fig 3b. The correlation coefficient and the second degree polynomial are given by $r=0.85$ and $y=$ $-1.99+1.23 \mathrm{X}-0.003 \mathrm{X}^{2}$ respectively. The correlation coefficient for linear fitting was found to be 0.82 .

3. In summer, the $I_{E C}$ max increases with $F_{10.7}$ up to about 240 units, after which saturation is observed at a value of approximately 100 TECU, as shown in Fig 3c. The correlation coefficient and the second degree polynomial are given by $r=0.86$ and $y=14.28+$ $0.87 \mathrm{X}-0.002 \mathrm{X}^{2}$ respectively. The correlation coefficient for linear fitting was found to be 0.83 .

3.3.2 Solar cycle-22 (1986-89) results. 1. In equinox season, $\mathrm{IEC}_{\max }$ is found to be positively correlated with $\mathrm{F}_{10.7}$ up to about 200 units after which it saturates at a value of approximately 150 TECU, as shown in Fig 4a. The correlation coefficient and the second degree 
polynomial are given by: $r=0.84$ and $y=16.78+$ $1.68 \mathrm{X}-0.005 \mathrm{X}^{2}$ respectively.

2. In winter, $\mathrm{IEC}_{\max }$ is found to increase with $\mathrm{F}_{10.7}$ up to about 240 units at which IEC $_{\max }$ is approximately 150 TECU, as shown in Fig 4b. The correlation coefficient and the second degree polynomial are given by $r=0.90$ and $y=7.08+1.54 \mathrm{X}-0.002 \mathrm{X}^{2}$ respectively.

3. In summer, $I_{E C}$ max is found to increase with $F_{10.7}$ up to about 240 units, after which $\mathrm{IEC}_{\max }$ saturates at a value of approximately $70 \mathrm{TECU}$, as shown in. Fig 4c Here the correlation coefficient and the second degree polynomial are given by $r=0.88$ and $y=20.95+$ $0.57 \mathrm{X}-0.002 \mathrm{X}^{2}$ respectively.

The results of non linear variation of $\mathrm{IEC}_{\max }$ with $\mathrm{F}_{10.7}$ in solar cycles 21 and 22 are almost of a similar nature. In general, we may say that $\mathrm{IEC}_{\max }$ increases
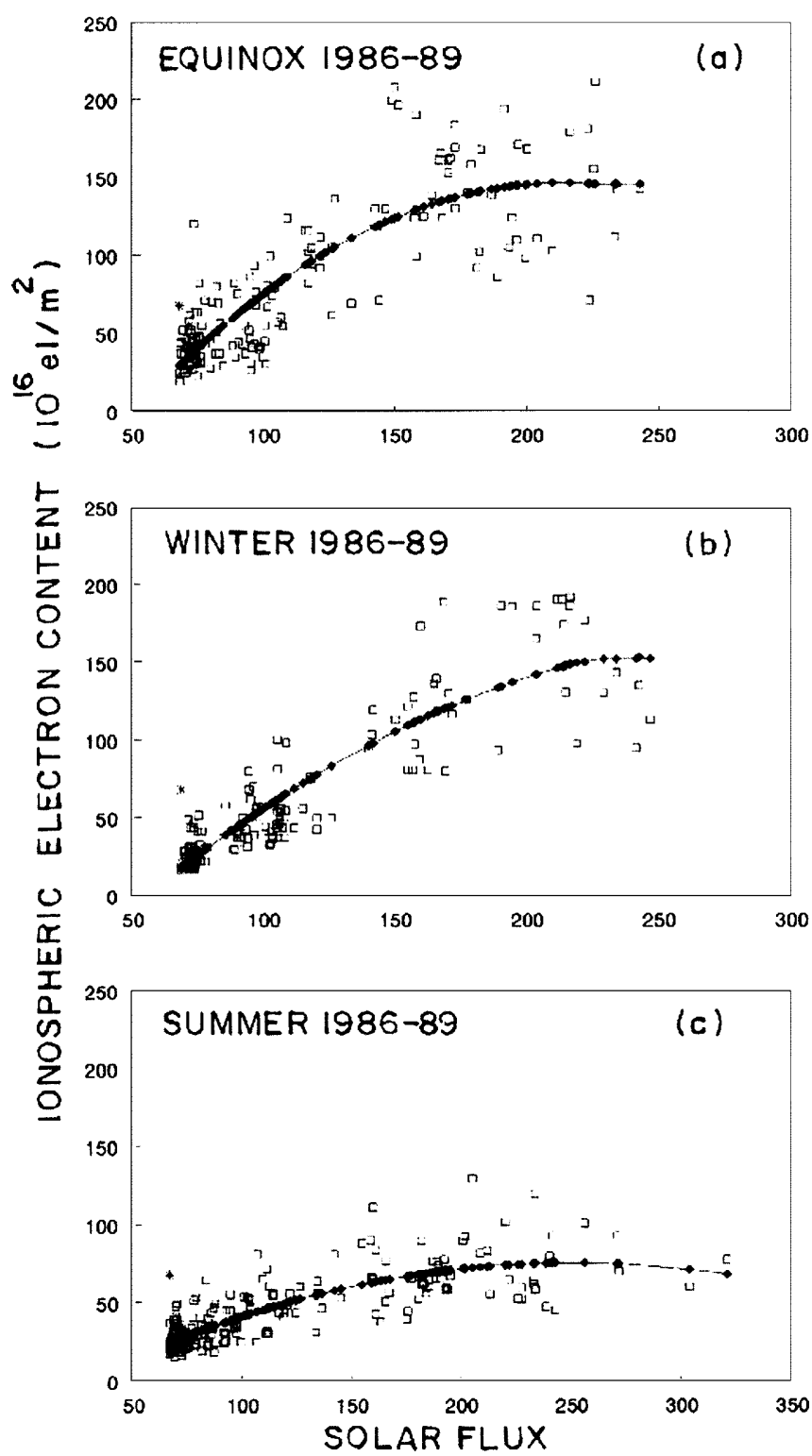

Fig. 4a-c. Variation of $\mathrm{IEC}_{\max }$ with solar flux $\left(\mathrm{F}_{10.7}\right)$ in solar cycle 22 for a equinox, $\mathbf{b}$ winter and $\mathbf{c}$ summer (the black diamonds show the points of 2 nd degree polynomial fitting) with $\mathrm{F}_{10.7}$ up to about 200-240 flux units depending upon season, after which it generally saturates at a value of approximately $70-150$ TECU which is seasonally dependent. The results are slightly better described in solar cycle-22 as IEC $_{\max }$ data for higher values of solar flux are available.

Bhuyan et al. (1983) and Rao et al. (1988) also reported saturation of $\mathrm{IEC}_{\max }$ at northern latitudes during solar cycle-21. Koparkar (1987) reported the relationship between IEC $_{\max }$ and $\mathrm{F}_{10.7}$ to be linear up to 150 TECU which agrees substantially with the present data. Prasad and Rama Rao (1993), using low solar activity data from Waltair (a station within the equatorial anomaly region), found a linear relationship between IEC $_{\max }$ and $\mathrm{F}_{10.7}$ up to 100 TECU. Their observations indicated that the correlation coefficient was higher (0.43) in summer than in equinox $(0.25)$ and winter (0.34). They also found that the gradient of IEC $_{\max }$ versus solar flux in winter was more than that in equinox and summer, compared with the present observations of minimum gradients in summer but maximum gradients in equinox. Balan et al. (1993) found the $\mathrm{IEC}_{\max }$ increasing linearly with $\mathrm{F}_{10.7}$ up to about 200 flux units and saturation at higher flux values at all latitudes from $17^{\circ} \mathrm{N}$ to $47^{\circ} \mathrm{N}$, and in all the seasons. They found convincing ionospheric evidence of a non-linear relationship between the solar EUV and $10.7 \mathrm{~cm}$ solar fluxes during intense solar cycles. They also found that plots for magnetically quiet days showed less scatter compared with data observed on all magnetically active conditions.

\subsection{Magnetic activity control on IEC}

Solar wind affects the ionosphere by producing changes in the Earth's magnetic field and in particle precipitation. To study the control of geomagnetic activity on the ionosphere, IEC $_{\max }$ behaviour observed at Delhi is analysed. Jain et al. (1978), Dabas et al. (1980, 1984) and Kane (1981) studied the same phenomena using magnetic storms' data from $23^{\circ} \mathrm{N}-30^{\circ} \mathrm{N}$ latitudes in low solar activity, and inferred that $\mathrm{IEC}_{\max }$ does not show any systematic variation during magnetic storms. As distinct from the behaviour during magnetic storms, Koparkar (1987) examined the average behaviour during low solar activity using data from Bombay (geographic co-ordinates: $18.55^{\circ} \mathrm{N}, 72.55^{\circ} \mathrm{E}$; geomagnetic co-ordinates: $9.58^{\circ} \mathrm{N}, 143.28^{\circ} \mathrm{E}$ ). She also found that IEC $_{\max }$ did not have any clear dependence on $A_{p}$. Prasad and Rama Rao (1993) using Waltair IEC $\max$ data also did not find any clear dependence on $A_{p}$ during low, as well as high, solar activity. The absence of any significant correlation between $\mathrm{IEC}_{\max }$ and $A_{p}$ may partly be due to the averaging effect of quiet and disturbed day indices which the authors have not taken into account. In the present study storm days' data have been excluded.

Another difficulty in studying the control of magnetic activity over an extended period is that changing solar activity also affects the $\mathrm{IEC}_{\max }$. Therefore, to minimise 
solar activity bias, the data are grouped into two periods: (1) low solar activity and (2) high solar activity. For the low solar activity period, IEC $_{\max }$ data having $\mathrm{F}_{10.7}$ in the range from $60-100$ units is used whereas for high solar activity, $\mathrm{F}_{10.7}$ in the range of $180-220$ units is used. The correlation coefficients of IEC $_{\max }$ with $A_{p}$ in low as well as high solar activity for solar cycles 21 and 22 are presented in Table 2. Other results of the study are given:

3.4.1 Solar cycle-21 (1975-80). 1. Low solar activity (1975-76) results: in equinox, IEC $_{\max }$ is independent of $A_{p}$. It is found to increase linearly with $A_{p}$ in winter and summer.

2. High solar activity (1979-80) results: IEC $_{\max }$ is found to decrease linearly with $A_{p}$ in equinox and winter whereas in summer it shows slight increase with $A_{p}$.

3.4.2 Solar cycle-22 (1986-89). 1. Low solar activity (1986) results: in equinox, IEC $_{\max }$ is almost independent of $A_{p}$ whereas it increases linearly with $A_{p}$ in winter and summer.

2. High solar activity (1989) results: while in equinox IEC $_{\max }$ shows a linear increase with $A_{p}$, in winter it decreases linearly with $A_{p}$ and in summer it again increases with $A_{p}$.

From the low solar activity results of solar cycles 21 and 22, the linear relationship of $\mathrm{IEC}_{\max }$ and $A_{p}$ is seen to be similar in all seasons. However, the gradients are greater in all the seasons of 1986 compared with those in the seasons of 1975-76. During the high solar activity period of $1980, \mathrm{IEC}_{\max }$ and $A_{p}$ are more or less independent in equinox and summer, but they show negative correlation in winter, whereas in 1989 there is a good positive linear relationship between IEC $_{\max }$ and $A_{p}$ during equinox and summer, but winter 1989 shows linear decrease.

\section{Day-to-day variability in IEC}

The large day-to-day variability in $\mathrm{IEC}_{\max }$ has been observed world wide, irrespective of geographic location, local time, season of the year, solar EUV flux and magnetic activity conditions. On a given day at any one location, changes in $\mathrm{IEC}_{\max }$ up to one order of magnitude are common. Lakha Singh et al. (1996) compared the actual Faraday rotation (FR) observations monitored at Delhi with Faraday rotation com- puted from Option-II of the International Reference Ionosphere (IRI) model (Bilitza, 1990) and reported that the IRI (1990) model grossly overestimates the daytime as well as night time FR in low (1975-76) and high solar activity (1980) periods. During low solar activity (197576), the daytime overestimations in FR in all seasons are found to lie between 185 and $320 \%$. and post-midnight overestimations in FR values lie in the range of 130 $205 \%$ and $95-200 \%$ respectively. During high solar activity (1980), the daytime FR values predicted by the IRI are overestimated by 70 to $110 \%$. The pre-midnight and post-midnight values are also overestimated by 55 to $115 \%$ and 100 to $280 \%$ respectively. However, in the $0500-0600 \mathrm{~h}$ time slot, the estimates are within $20 \%$ in all seasons during low solar activity and in winter and autumnal equinox of high solar activity. Though a number of theories have been put forward by various workers to explain the day-to-day variability in ionospheric electron content, many events could not be explained.

To study the day-to-day changes in daytime $\mathrm{IEC}_{\max }$, data obtained at Delhi during ascending phases of solar activity during 1975-80 (solar cycle-21) and 1986-89 (solar cycle-22) are used. The variations in daytime IEC $_{\max }$ on a day-to-day basis observed in this study may be classified into three categories i.e. single-day, alternate-day and long-term variability, as discussed next.

\subsection{Single-day abnormality}

A single day abnormality in IEC $_{\max }$ is one which is observed on a particular day only, i.e. on this day the IEC $_{\text {max }}$ is high or low compared to that on the preceding and following days. There are six cases of single day abnormality worth noting in 1975-76, whereas in 1986 ten such cases are present. It is found that they have no pattern with regard to their seasonal occurrence. Figure 5a shows an example of a single day abnormality observed on April 21, 1986, when magnetic activity and solar activity were found to be normal, but the electrojet strength showed some abnormal behaviour during this period. This shows that this single day abnormal increase in $\mathrm{IEC}_{\max }$ may have a correlation with electrojet strength. Sometimes the single day abnormality does not show any correlation with $\mathrm{F}_{10.7}, \Delta H$ (defined as the change in the horizontal component of the geomagnetic field) and $A_{p}$. A single day abnormality may be of localised nature. The present results agree well with

Table 2. Correlation coefficients of $\mathrm{IEC}_{\max }$ with $\mathrm{F}_{10.7}$ and $A_{p}$

\begin{tabular}{|c|c|c|c|c|c|c|}
\hline Seasons & \multicolumn{3}{|c|}{ Solar cycle-21 (1975-80) results } & \multicolumn{3}{|c|}{ Solar cycle-22 (1986-89) results } \\
\hline Equinox & 0.88 & -0.001 & -0.113 & 0.84 & 0.003 & 0.32 \\
\hline Winter & 0.85 & 0.404 & -0.285 & 0.90 & 0.310 & -0.36 \\
\hline Summer & 0.86 & 0.166 & 0.056 & 0.88 & 0.320 & 0.41 \\
\hline
\end{tabular}



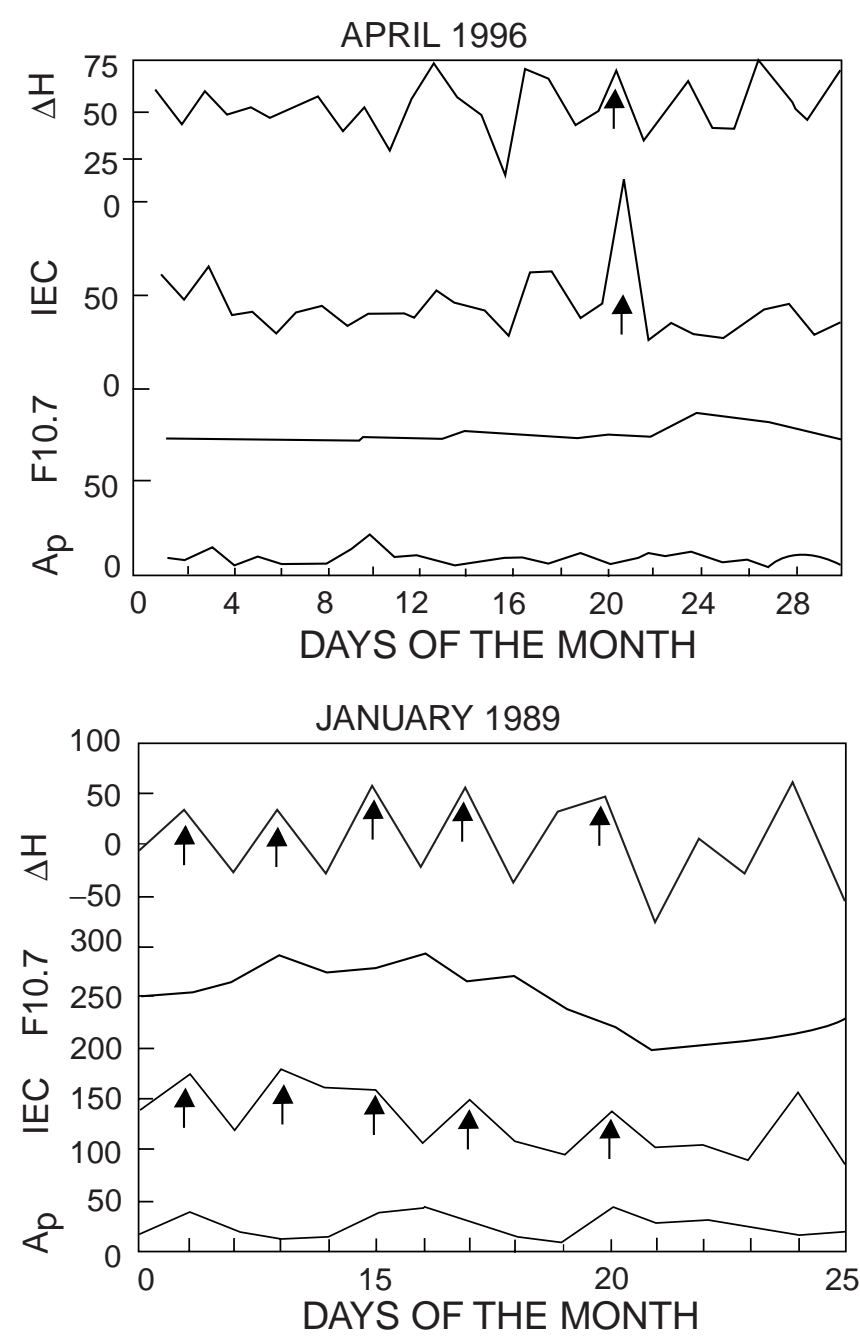

Fig. 5. a Single day and $\mathbf{b}$ alternate day abnormalities in $I \mathrm{CC}_{\max }$ $\left(10^{16} \mathrm{el} / \mathrm{m}^{2}\right)$ and $\Delta H$ (nano Tesla, nT) but not in $\mathrm{F}_{10.7}\left(10^{-22}\right.$ Watts/ square meter/cycle per second bandwidth) and $A_{p}$

those of Tyagi and Mitra (1970) and Tyagi (1978) for Delhi, and Dabas et al. (1984) for locations around the crest of the equatorial anomaly; these workers found the single day abnormality events of localised nature. They attributed abnormal increases in daytime IEC $_{\max }$ during low solar activity to temperature and composition changes in the thermosphere. Jayachandran et al. (1995) found that short-term day-to-day variability in IEC $_{\text {max }}$ did not have any dependence on solar flux at low latitudes. At temperate latitudes, Rama Rao et al. (1981) interpreted the day-to-day changes in the Fregion as being due to changes in local atmospheric conditions in the thermosphere. At middle latitudes, Kane (1975) suggested that the day-to-day variability in $\mathrm{IEC}_{\max }$ is due to erratic equatorward neutral winds that originate in polar regions intermittently even under quiet conditions, creating convective cells that wander slowly around the globe, and result in ionospheric irregularities of scale length about $3000 \mathrm{~km}$.

Single day abnormality in $\mathrm{IEC}_{\max }$ is not restricted to low solar activity only; it is observed during high solar activity also. There are a few cases showing single day abnormality features in 1979 and 1989, but increases in $\mathrm{IEC}_{\max }$ on these days are always found to be associated with increases in one or more of the geophysical parameters $\Delta H, \mathrm{~F}_{10.7}$ or $A_{p}$. This is as expected, and not simply a localised effect.

\subsection{Alternate day abnormality}

IEC $_{\max }$ also shows increase and decrease on alternate days for a few days continuously. This is called alternate day abnormality. IEC $_{\max }$ values are found to fluctuate for many days during low as well as high solar activity at Delhi. From Fig. 5b which shows alternate days fluctuations in $\mathrm{IEC}_{\max }$ for several days during January 1989, it is obvious that there is no substantial variation in the values of magnetic activity $\left(A_{p}\right)$ and solar flux $\left(\mathrm{F}_{10.7}\right)$, whereas equatorial electrojet parameter $(\Delta H)$ fluctuates almost in unison with IEC $_{\max }$. There is almost one-toone correspondence between daytime $\mathrm{IEC}_{\max }$ and equatorial electrojet strength. Similar behaviour has also been observed in low solar activity. This shows that IEC $_{\max }$ values are affected by the strength of the equatorial electrojet observed at Delhi in low, as well as in high, solar activity of both solar cycles. Dabas et al. (1984) reported one-to-one correspondence of equatorial electrojet strength with $\mathrm{IEC}_{\max }$ recorded in November 1975 even at Patiala (geographic co-ordinates: $30.20^{\circ} \mathrm{N}, \quad 76.25^{\circ} \mathrm{E}$; geomagnetic co-ordinates: $20.74^{\circ} \mathrm{N}, 148.21^{\circ} \mathrm{E}$ ) which is considered to be outside the anomaly belt. Rama Rao et al. (1994) found day-today IEC $_{\max }$ variations to be controlled by equatorial electrojet strength at Waltair during summer. Prasad and Rama Rao (1993) also found day-to-day changes in IEC $_{\max }$ at Waltair particularly in summer during low solar activity, and inferred that the changes are mainly controlled by the strength of the equatorial electrojet. Alex and Rastogi (1989) observed more day-to-day variations at Ahmedabad (geographic co-ordinates: $23.03^{\circ} \mathrm{N}, 72.40^{\circ} \mathrm{E}$; geomagnetic co-ordinates: $14.05^{\circ} \mathrm{N}$, $143.71^{\circ} \mathrm{E}$ ) which is situated near the crest of equatorial anomaly region, than at the equatorial stations of Ootacamund (geographic co-ordinates: $11.24^{\circ} \mathrm{N}$, $76.44^{\circ} \mathrm{E}$; geomagnetic co-ordinates: $1.88^{\circ} \mathrm{N}, 146.77^{\circ} \mathrm{E}$ ) and Kodaikanal (geographic co-ordinates: $10.13^{\circ} \mathrm{N}$, $77.32^{\circ} \mathrm{E}$; geomagnetic co-ordinates: $0.69^{\circ} \mathrm{N}, 146.91^{\circ} \mathrm{E}$ ) and Huancayo (geographic co-ordinates: $12^{\circ} \mathrm{S}, 284.7^{\circ} \mathrm{E}$; geomagnetic co-ordinates: $\left.0.7^{\circ} \mathrm{S}, 186.1^{\circ} \mathrm{E}\right)$. They explained their observations as being due to the resultant effect of dumping of ionisation at these latitudes through the equatorial 'fountain effect'.

The alternate day variability or two-day oscillation of the ionospheric electron content and equatorial electrojet may be attributed to the planetary waves which have a period of more than one day. The planetary wave with a period of two days modulates the tidal wind which results in alternate day oscillation of equatorial electrojet which in turn controls the IEC $_{\max }$ within the equatorial anomaly region. Pei-RenChen (1992) has confirmed this relationship using numerical simulation. 
Deshpande et al. (1977), Sethia et al. (1980) and Lakshmi et al. (1985) showed that there exists a close correlation between the development of equatorial anomaly in $\mathrm{IEC}_{\max }$ and the electrojet strength at the crest location whereas there exists no such correlation at the equator. Dabas et al. (1984) studied the day-to-day changes in $\mathrm{IEC}_{\max }$ using multi-station data covering the $15^{\circ} \mathrm{N}-30^{\circ} \mathrm{N}$ latitude range in the Indian zone during solar minimum. They found that short-term, as well as long-term variations in the daytime maximum electron content within and near the crest of the equatorial belt are mainly controlled by the equatorial electrojet strength. Alex and Rastogi (1989) found the day-today variability in $\mathrm{IEC}_{\max }$ at the crest location of Ahmedabad higher than the equatorial values, and attributed this to day-to-day changes in the equatorial electric field.

Dabas et al. (1984) studied the diurnal variation of the average percentage variation of $I \mathrm{CC}_{\max }$ during quiet (QQ) and disturbed (DD) days. They found the QQ and $\mathrm{DD}$ (time variations of $\mathrm{IEC}_{\max }$ ) to be mirror images of each other at low latitudes at Ahmedabad, Gauhati (geographic co-ordinates: $26.11^{\circ} \mathrm{N}, 91.47^{\circ} \mathrm{E}$; geomagnetic co-ordinates: $15.41^{\circ} \mathrm{N}, 161.86^{\circ} \mathrm{E}$ ) and Patiala in winter for all local times, and in summer at Kurukshetra (geographic co-ordinates: $29.9^{\circ} \mathrm{N}, 76.8^{\circ} \mathrm{E}$; geomagnetic co-ordinates: $20.39^{\circ} \mathrm{N}, 148.68^{\circ} \mathrm{E}$ ). Prasad and Rama Rao (1993), using Waltair IEC $_{\max }$ data observed QQ and DD curves to be the mirror images of each other excepting at about $0700 \mathrm{~h} \mathrm{LT}$ in summer in low, as well as in high, solar activity periods. They reported that although no direct correlation with magnetic activity is apparent, there is a systematically higher variability on QQ than on DD days in daytime hours of winter months in low solar activity period. However, Arvindan and Iyer (1990) using Hawaii (geographic co-ordinates: $20^{\circ} \mathrm{N}, 155^{\circ} \mathrm{W}$; geomagnetic co-ordinates: $11.71^{\circ} \mathrm{N}$, $221.81^{\circ} \mathrm{E}$ ) data found a systematically higher variability on $\mathrm{DD}$ days than on $\mathrm{QQ}$ days during daytime in high solar activity periods. No significant difference between quiet and disturbed day values is found at Tokyo (geographic co-ordinates: $35.40^{\circ} \mathrm{N}, 138.45^{\circ} \mathrm{E}$; geomagnetic co-ordinates: $25.45^{\circ} \mathrm{N}, 154.51^{\circ} \mathrm{E}$ ).

\subsection{Longterm periodic fluctuations}

Apart from shortterm fluctuations in $\mathrm{IEC}_{\max }$ values, long-term periodic variations from the average values have also been observed at Delhi. During a high solar activity period of 1979 (March, November and December), a 27-day periodicity was observed in $\mathrm{IEC}_{\max }$. In equinox, the 27-day periodicity in IEC $_{\max }$ is accompanied by similar variations in $\mathrm{F}_{10.7}$, but $\Delta H$ and $A_{p}$ do not show such periodicity. In November and December, a 27-day periodicity is found in $\mathrm{IEC}_{\max }, \mathrm{F}_{10.7}$ and $\Delta H$, but no such periodicity is observed in $A_{p}$. Figure 6 shows 15 day running means of the data from November 1988 to February 1989 (winter). The running means were taken to reduce the scatter. A 27-day variation in $I C_{\max }$ and $\mathrm{F}_{10.7}$ solar flux is clearly seen from the figure. Dabas
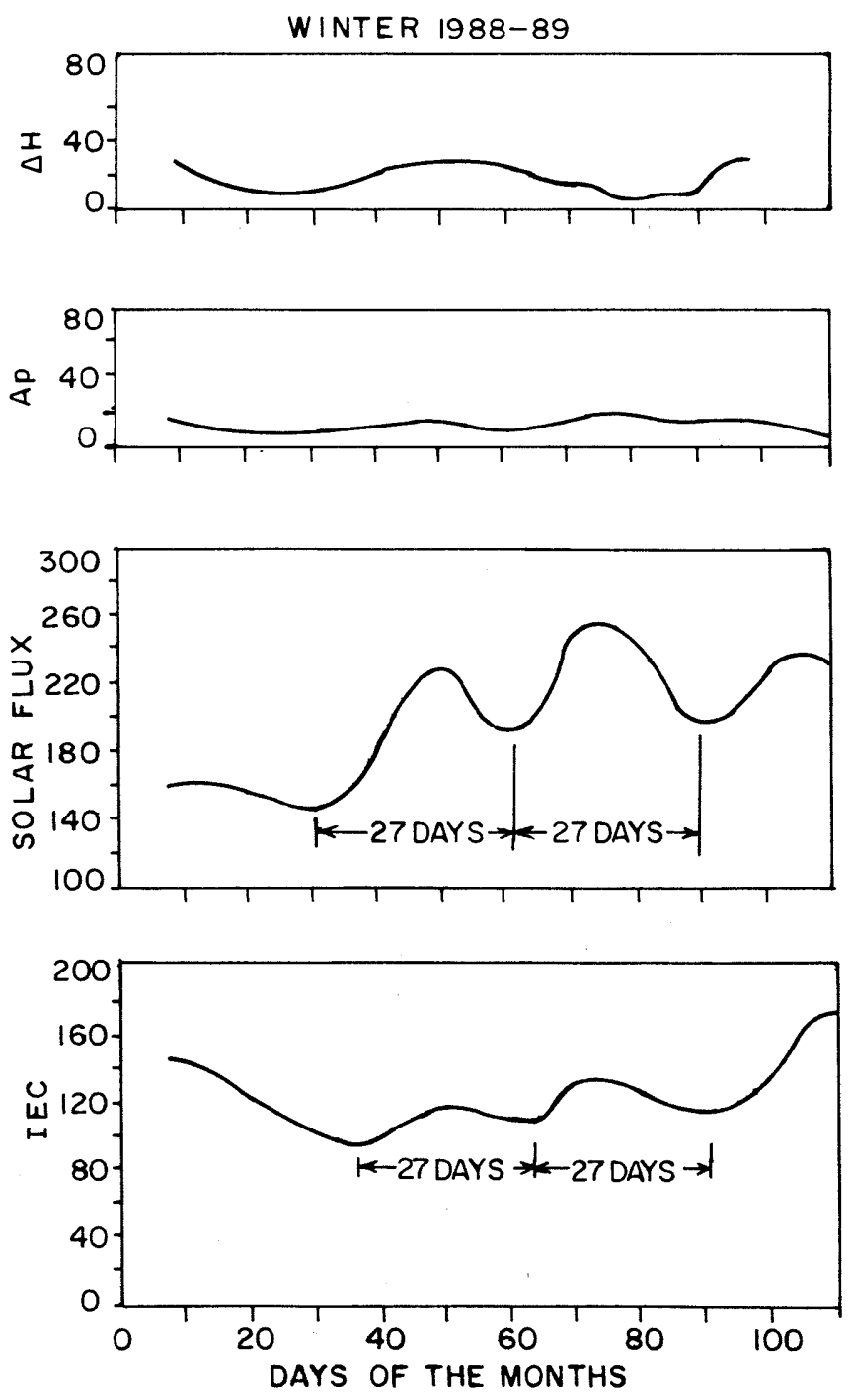

Fig. 6. Diagram showing 27-day periodicity in $\operatorname{IEC}_{\max }\left(10^{16} \mathrm{el} / \mathrm{m}^{2}\right)$ and solar flux, $\mathrm{F}_{10.7}\left(10^{-22}\right.$ Watts/square meter/cycle per second bandwidth), but not in $\Delta \mathrm{H}$ (nano Tesla, nT) and $A_{p}$

et al. (1984) also observed that in summer, IEC max $_{\max }$ shows a periodicity of about 27-days at Delhi, Ahmedabad, Gauhati and Bombay which is similar to the solar flux variation, and also to the variation in the electrojet strength. However, shortterm variations are again mainly controlled by electrojet strength, and not by solar flux which shows small variability.

Annual and semi-annual variations in $\mathrm{IEC}_{\max }$ are quite evident from the data of solar cycle 21 and 22 at Delhi during low, as well as high, solar activity periods. Figure 7 shows that the annual and semi-annual fluctuations in $\mathrm{IEC}_{\max }$ tend to be in phase with equatorial electrojet variations. Such periodic variations are not seen in $A_{p}$ and $\mathrm{F}_{10.7}$ at Delhi. Bhuyan (1992) found annual and semi-annual variations in $\mathrm{IEC}_{\max }$ at Lunping under all levels of solar activity. Based on calculations of scale height of the absorbing gas, it is found that in equinoctial months, solar radiation is absorbed mainly by atomic oxygen. This causes high values of $\mathrm{IEC}_{\max }$ in the equinoxes (March and October), and is 


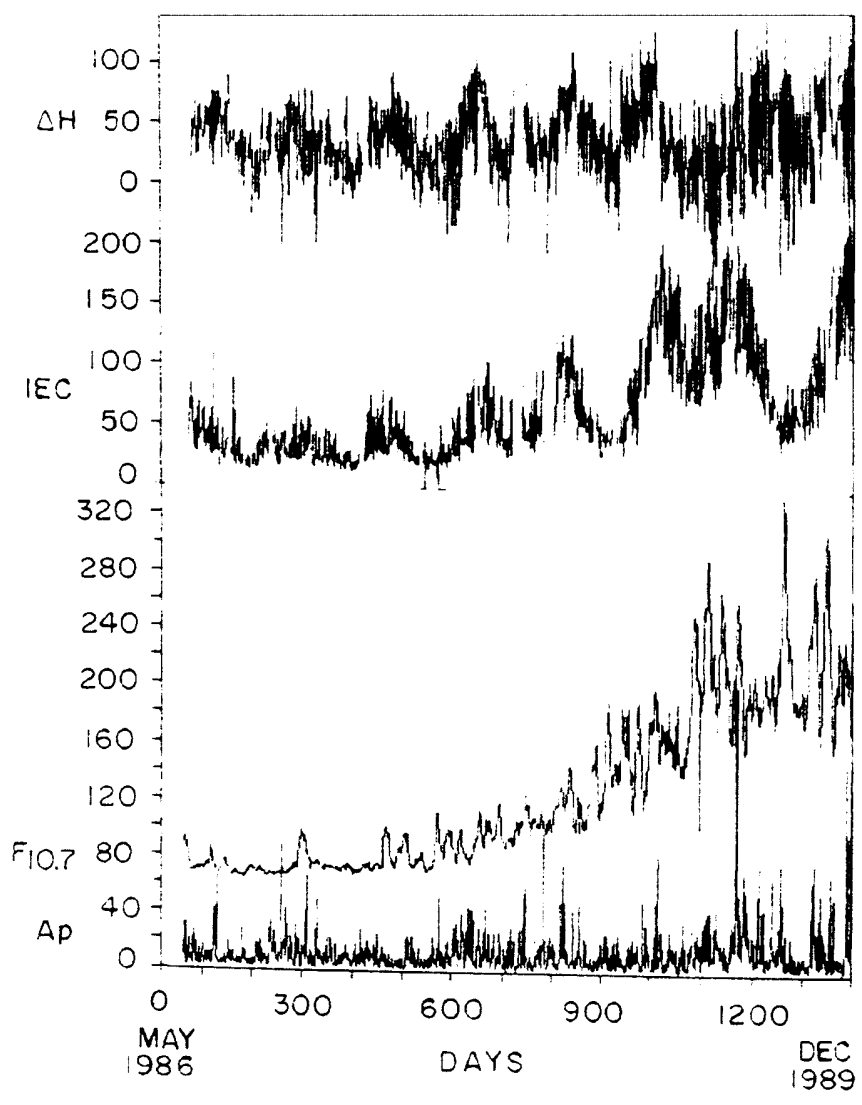

Fig. 7. Semi-annual and annual variations in $\operatorname{IEC}_{\max }\left(10^{16} \mathrm{el} / \mathrm{m}^{2}\right)$ and $\Delta H$ (nano Tesla, nT) but not in $\mathrm{F}_{10.7}\left(10^{-22}\right.$ Watts/square meter/ cycle per second bandwidth) and $A_{p}$ during solar cycle 22

responsible for semi-annual variations. Low IEC $_{\max }$ is observed in winter when solar activity is low and also in summer when solar activity is high. This gives rise to annual variations in IEC $_{\text {max }}$ during both low and high solar activity periods. Mayr and Mahajan (1971) have shown that the observed variation in the neutral composition ratios, $\mathrm{O} / \mathrm{O}_{2}$ and $\mathrm{O} / \mathrm{N}_{2}$, is sufficient to produce semiannual variations in the $F_{2}$ maximum density. Titheridge (1973) has attributed this to changes in global atmospheric circulation at the equinox, giving a rapid decrease in the loss rate and a change in the pattern of vertical drifts. Prasad et al. (1987) using 1978 IEC $_{\max }$ data of Waltair noted the semi-annual variation in IEC $_{\max }$ which they explained on the basis of the strong control which the sun's radiation exerts on the ionisation density during equinoxes.

Huang and Cheng (1995) using Lunping IEC $_{\max }$ data also observed two maxima and two minima annually during high solar activity. In general, IEC max $_{\text {ax }}$ comparable values in both the solar cycles in low solar activity, whereas in high solar activity IEC $_{\max }$ is found to be slightly more (220 TECU) in solar cycle 22 as compared to (200 TECU) in solar cycle 21 at Delhi. Koparkar (1987) reported that in low solar activity of 1984 IEC $_{\max }$ was double that of 1975-76 at Bombay, close to the anomaly peak, but it is not so at Delhi.

IEC $_{\max }$ variations observed at Delhi appear to be controlled by the equatorial electrojet strength and are related to the coupling between the equatorial and low latitude ionisation as a result of electrodynamic drift and diffusion. The F-region ionisation between $\pm 15^{\circ}$ dip latitudes is dominantly controlled by the well-known 'fountain effect'. A strong electrojet implies a larger $\mathbf{E} \times \mathbf{B}$ drift at the magnetic equator, and the development of a pronounced equatorial anomaly. Hence the observed day-to-day variability of $\mathrm{IEC}_{\max }$ at low latitudes, and its correlation with $\Delta H$ variability, is a manifestation of the electrodynamic coupling between the equatorial and low-latitude ionosphere. Thus the present study made at Delhi of day-to-day variability based on $I C_{\max }$ data and other geophysical parameters for varying levels of solar activity, supports the conclusions of previous studies, and highlights the importance of electrodynamic coupling between the equatorial and low latitude ionosphere.

\section{Conclusion}

Data spread over two solar cycles have been utilised to examine the response of the ionosphere over Delhi for various geophysical conditions using ionospheric electron content as a parameter. Data for abnormal conditions (disturbed days) have not been included. The diurnal variation of seasonal mean of IEC on quiet days shows a secondary peak comparable to the daytime peak in equinox and winter in high solar activity. This may be produced by the combined effect of meridional winds and $\mathbf{E} \times \mathbf{B}$ drifts. IEC $_{\max }$ shows winter anomaly only during high solar activity at Delhi. Composition changes (Titheridge and Buonsanto, 1983) and decrease of $\mathrm{O}^{+}$density during summer due to vibrational excitation of $\mathrm{N}_{2}$ may be responsible for the seasonal anomaly (Torr et al., 1980; Richards and Torr, 1986). IEC $_{\max }$ shows positive correlation with $\mathrm{F}_{10.7}$ up to about 200 flux units in equinox and 240 units both in winter and summer; for greater $F_{10.7}$ values, IEC max $_{\text {max }}$ is substantially constant in all the seasons. IEC $\mathrm{Imax}_{\text {and }}$ magnetic activity $\left(A_{p}\right)$ are found to be positively correlated in summer in high solar activity. This is in conformity with the results of Balan et al. (1993) at different latitudes. Winter IEC $_{\max }$ shows positive correlation with $A_{p}$ in low solar activity and negative correlation in high solar activity in both the solar cycles. In equinox $\mathrm{IEC}_{\max }$ is independent of $A_{p}$ in both solar cycles in low solar activity. A study of day-to-day variations in $\mathrm{IEC}_{\max }$ shows single day and alternate day abnormalities, semi-annual and annual variations. It is found that $\mathrm{IEC}_{\max }$ values observed at Delhi during low as well as high solar activity of both solar cycles are affected by strength of the equatorial electrojet. Alternate day abnormalities may have been produced by planetary scale waves. The results have been compared with IRI (1990) model and found that actual FR observations and those derived from the model differ to a great extent at low latitudes.

Acknowledgements. Topical Editor M. Lester thanks E.A. Engi and G. Goodwin for their help in evaluating this paper. 


\section{References}

Alex, S., and R. G. Rastogi, Day-to-day variability of maximum electron density and ionospheric electron content at equatorial stations, Ind. J. Radio Space Phys., 18, 99-102, 1989.

Arvindan, P., and K. N. Iyer, Day-to-day variability in ionospheric electron content at low latitudes, Planet. Space Sci., 38, 743750, 1990.

Balan, N., G. J. Bailey, and B. Jayachandran, Ionospheric evidence for a nonlinear relationship between the solar e.u.v. and $10.7 \mathrm{~cm}$ fluxes during an intense solar cycle, Planet Space Sci., 41, 141145, 1993.

Bhuyan, P. K., Diurnal, seasonal and solar cycle variation of TEC, NmF2 and slab thickness at Lunping, Ind. J. Radio Space Phys., 21, 170-178, 1992.

Bhuyan, P. K., T. R. Tyagi, Lakha Singh, and Y. V. Somayajulu, Ionospheric electron content measurements at a northern low mid-latitude station through half a solar cycle, Ind. J. Radio Space Phys., 12, 84-93, 1983.

Bilitza, D., International Reference Ionosphere, 1990, National Space Science/World Data Center-A for Rockets and Satellites, 90-22, 1990.

Chakraborty, S. K., A. Das Gupta, S. Ray, and S Banerjee, Longterm observations of VHF scintillation and total electron content near the crest of the equatorial anomaly in the Indian longitude zone, Radio Sci., 34, 241-255, 1999.

Chandra, H., and R. G. Rastogi, Geomagnetic storm effects on ionospheric drifts and the equatorial $\mathrm{E}_{\mathrm{s}}$ over the magnetic equator, Ind. J. Radio Space Phys., 3, 332-336, 1974.

Chen, Pei-Ren, Two-day oscillation of the equatorial ionization anomaly, J. Geophys. Res., 97(A5), 6343-6357, 1992.

Dabas, R. S., J. B. Lal, T. R. Tyagi, and Y. V. Somayajulu, Variations of total electron content and other ionospheric parameters associated with magnetic storms, Ind. J. Radio space Phys., 9, 1-6, 1980.

Dabas, R. S., P. K. Bhuyan, T. R. Tyagi, R. K. Bhardwaj, and J. B. Lal, Day-to-day changes in ionospheric electron content at low latitudes, Radio Sci., 19, 749-756, 1984.

Dabas, R. S., D. R. Lakshmi, and B. M. Reddy, Solar activity dependence of ionospheric electron content and slab thickness using different solar indices, PAGEOPH (France), 140, 721728, 1993.

Davies, K., Remote sensing of the ionosphere using satellite beacons, Ind. J. Radio Space Phys., 20, 356-367, 1991.

Deshpande, M. R., R. G. Rastogi, H. O. Vats, J. A. Klobuchar, G. Sethia, A. R. Jain, B. S. Subba Rao, V. M. Patawari, A. V. Janve, R. K. Rai, Malkiat Singh, H. S. Gurm, and B. S. Murthy, Effect of electrojet on total electron content of the ionosphere over the Indian sub-continent, Nature, 267, 599-600, 1977.

Garg, S. C., P. N. Vijayakumar, L. Singh, T. R. Tyagi, and Y. V. Somayajulu, Early results of ATS-6 radio beacon experiment at New Delhi, Ind. J. Radio Space Phys., 6, 190-196, 1977.

Garg, S. C., Y. V. Somayajulu, Lakha Singh, and T. R. Tyagi, Evidence of the development and decay of a post sunset equatorial anomaly at low latitudes, Proc. International Symposium on "Beacon Satellite studies of the earth's environment" held at National Physical Laboratory, New Delhi, India, 359-373, 1983.

Huang, Y. N., and K. Cheng, Solar cycle variation of the total electron content around equatorial anomaly crest region in east Asia, J. Atmos. Terr. Phys., 57, 1503-1511, 1995.

Jain, A. R., M. R. Deshpande, G. Sethia, R. G. Rastogi, Malkiat Singh, H. S. Gurm, A. V. Janve, and R. K. Rai, Geomagnetic storm effects on ionospheric electron content in Indian zone, Ind. J. Radio Space Phys., 7, 111-118, 1978.

Jayachandran, B., R. B. Nair, N. Balan, and P. B. Rao, Short term variabilities of ionospheric electron content (IEC) and peak electron density (NP) during solar cycles 20 and 21 for a low latitude station, J. Atmos. Terr. Phys., 57, 1599-1609, 1995.

Kane, R. P., Day-to-day variability of ionospheric electron content at mid-latitudes, J. Geophys. Res., 80, 3091-3099, 1975.
Kane, R. P., Storm effects of ionospheric total electron content at low latitudes, J. Geomagn. Geoelectr., 33, 399-409, 1981.

Kelley, M. C., The Earth's ionosphere, Academic Press, San Diego, 1989.

Koparkar, P., Ionospheric electron content measurements at Bombay, a station close to Appleton anomaly peak region, Ind. J. Radio Space Phys., 16, 408-410, 1987.

Lakshmi, D. R., R. S. Dabas, and B. M. Reddy, Relationship between short-term variations in electron content and foF2 over the Indian zone, Ind. J. Radio Space Phys., 14, 117-121, 1985.

Malkiat Singh, H. S. Gurm, and A. R. Jain, Equatorial electrojet and total electron content anomaly, Ind. J. Radio Space Phys., 8, 44-46, 1979.

Mayr, H. G., and K. K. Mahajan, Seasonal variation in the F2 region, J. Geophys. Res., 76, 1017-1027, 1971.

Modi, R. P., and K. N. Iyer, Ionospheric electron content near the peak of the equatorial anomaly in Indian zone during solar maximum, Ind. J. Radio Space Phys., 17, 98-102, 1988.

Prasad, D. S. V. V. D., and P. V. S. Rama Rao, Day-to-day variability of ionospheric electron content over Waltair, Ind. J. Radio Space Phys., 22, 391-396, 1993.

Prasad, D. S. V. V. D., K. Niranjan, and P. V. S. Rama Rao, TEC and equivalent slab thickness at low and mid latitudes - a comparative study, Ind. J. Radio Space Phys., 16, 295-299, 1987.

Rama Rao, P. V. S., P. Sriram, and P. T. Jayachandran, Short- and long-term variations in IEC over Waltair, Ind. J. Radio Space Phys., 23, 340-346, 1994.

Rama Rao, P. V. S., D. Nru, and M. Srirama Rao, Study of some low latitude ionospheric phenomena observed in TEC measurements at Waltair, India, in Scientific and Engineering uses of Satellite Radio Beacons, Proc. COSPAR/URSI Symposium, Warszawa, Poland, May 19-23, 1980, Ed A. W. Wernik, 175187, Polish Scientific Publishers, Warsaw, 1981.

Rao, P. B., B. Jayachandran, and N. Balan, Low latitude TEC and $N p$ variations during the solar cycles 20 and 21, Proc. URSI Intl. Beacon Satellite Symposium, Beijing, China, p. 241-249, 1988.

Richards, P. G., and D. G. Torr, A factor of 2 reduction in theoretical F2 peak electron density due to enhanced vibrational excitation of $\mathrm{N}_{2}$ in summer at solar maximum, J. Geophys. Res., 91, 11331-11336, 1986.

Rishbeth, H., and C. S. G. K. Setty, The F-layer at sunrise, J. Atmos. Terr. Phys., 20, 263-276, 1961.

Sethia, G., R. G. Rastogi, M. R. Deshpande, and H. Chandra, Equatorial electrojet control of the low latitude ionosphere, J. Geomag. Geoelectr., 32, 207-216, 1980.

Singh, L., J. K. Gupta, and T. R. Tyagi, Comparison of Faraday rotation observations at Delhi with IRI model, $A d v$. Space Res. 18, 241-244, 1996.

Titheridge, J. E., The electron content of the southern mid-latitude ionosphere, 1965-71, J. Atmos. Terr. Phys., 35, 981-1001, 1973.

Titheridge, J. E., Winds in the ionosphere: a review, J. Atmos. Terr. Phys., 57, 1681-1714, 1995.

Titheridge, J. E., and M. J. Buonsanto, Annual variations in the electron content and height of the $\mathrm{F}$ layer in the northern and southern hemispheres, related to neutral composition, J. Atmos. Terr. Phys., 45, 683-696, 1983.

Torr, D. G., M. R. Torr, and P. G. Richards, Causes of the F-region winter anomaly, Geophys. Res. Lett., 7, 1980.

Tyagi, T. R, Day-to-day changes in ionospheric electron content, Proc. COSPAR Satellite Beacon Group Symposium, Florence, Italy 9-1 to 9-6, 1978.

Tyagi, T. R., and A. P. Mitra, Some geographic and geophysical aspects of total electron content of the ionosphere, J. Atmos. Terr. Phys., 32, 1807-1818, 1970.

Tyagi, T. R., and A. Das Gupta, Beacon satellite studies and modelling of total electron content of the ionosphere, Ind. J. Radio Space Phys., S K Mitra Memorial Special Issue, 424-438, Oct. 1990.

Yeh, K. C., and C. H. Liu, Motions in the ionosphere, Sci. Prog., Oxf., 63, 111-140, 1976. 